\title{
Bioweapons initiatives bogged down in talks
}

Erika Check, Washington

Bioweapons experts convene in Geneva, Switzerland, this week for fresh talks on the Biological Weapons Convention (BWC), the international treaty that seeks to counter the proliferation of such weapons.

But while the United States and some of its allies will use the occasion to exhort other nations to enact stronger biosecurity laws as called for by the treaty - their calls are likely to fall on deaf ears.

The United States and supporters such as Britain hope to use the meeting to convince other nations to enact strict pathogen-monitoring regimes and to draw up penalties for those who defy them. "We're convinced that the best way to approach these issues of pathogen security is at the national level," says Greg Stewart, a microbiologist seconded from the State University of West Georgia to the state department, and a US delegate to the talks.

Britain is keen that the talks are seen to produce results, meeting participants say, to demonstrate that international agreements are still relevant to global security issues. The meeting was arranged two years ago to prevent the BWC from collapsing after the United States opposed provisions to make the treaty binding on its signatory nations (see Nature 414, 675; 2001). But some observers say that the best they are hoping for from this week's meeting is that no

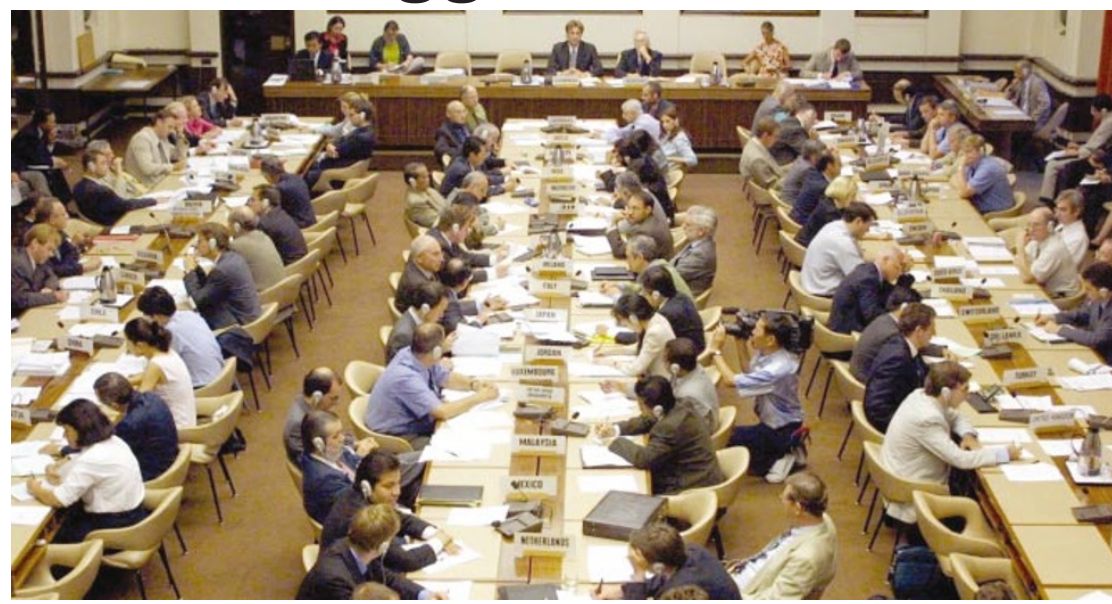

War of words: experts reconvene in Geneva this week to discuss controls over the spread of bioweapons.

fresh public recriminations will break out.

The talks are the first of three annual 'experts meetings', each to be followed by political summits, before the next major negotiations on the convention in 2006 . Delegates from most of the 146 signatories to the convention, and observers from non-governmental organizations, are due to discuss penalties for nations that violate the treaty, as well as biosecurity regulations. But with the treaty itself in limbo, the United States wants to use the meeting to build pressure for biological-weapons-control measures that fall outside the scope of the convention.

\section{Paired-up helium atoms make it big}

\section{Geoff Brumfiel, London}

Researchers at the Ecole Normale Supérieure (ENS) in Paris have coaxed two helium atoms together to create a supersized molecule up to 100 nanometres long - ending years of argument over whether such large molecules are possible.

Helium is an inert gas whose atoms don't like to form bonds with others. But under particular circumstances, the atoms can be brought together to form diatomic $\left(\mathrm{He}_{2}\right)$ molecules, says Jérémie Léonard, a graduate student at the ENS. Now, in work that will appear in a forthcoming issue of Physical Review Letters, his group has created a helium molecule far larger than any other ever made (J. Léonard et al. preprint at http://arxiv.org/cond-mat/0304446).

To create the molecules, Léonard and his colleagues cooled helium gas in a magnetic atom trap to extremely low temperatures about 10 microkelvin - and exposed it to infrared light. The infrared photons push the electrons to one side of the positively charged helium nuclei and make the atoms mildly attractive to each other, momentarily creating hundreds of thousands of loosely bound diatomic molecules.

Because the bond between the two component atoms is so weak, the molecules are up to a tenth of a micrometre long thousands of times larger than most simple molecules - and only hold together for about 50 nanoseconds. But that's still long enough for researchers to study the quantum behaviour of helium atoms and the way that they interact with others.

"There has been a lot of speculation over whether these molecules exist or not," says Peter van der Straten, a physicist at Utrecht University in the Netherlands, who used a similar technique to make smaller helium molecules in 2000 (N. Herschbach et al. Phys. Rev. Lett. 84, 1874-1877; 2000).

Van der Straten says he is impressed by the ENS group's work because the team managed to detect the minute amounts of heat given off by the giant helium molecules as they broke apart. This is the first time such detection has been achieved, he says.
Non-governmental organizations plan to use the forum to raise other issues related to arms control. Some are calling for tighter export controls and codes of conduct for governments. "We are entering a biological arms race, and European governments should be doing much more than spending two weeks in Geneva avoiding conflict," says Jan van Aken of the Sunshine Project, a nonprofit group based in Hamburg, Germany.

Others, such as Barbara Hatch Rosenberg of the Washington-based Federation of American Scientists, want the United Nations to reconstitute its weapons-inspections group as a permanent body that can be called on at a moment's notice. "In the past the inspections took too long to get started," she says.

A few participants hold out hope that the meeting will lend impetus to the revival of the BWC. But most think that such progress must await a change of administration in the United States. "It's not going to happen under this administration, but these talks have been going on since the 1960s and the issue is not going to go away," says Marie Chevrier, a political scientist at the University of Texas at Dallas who works with the Federation of American Scientists.

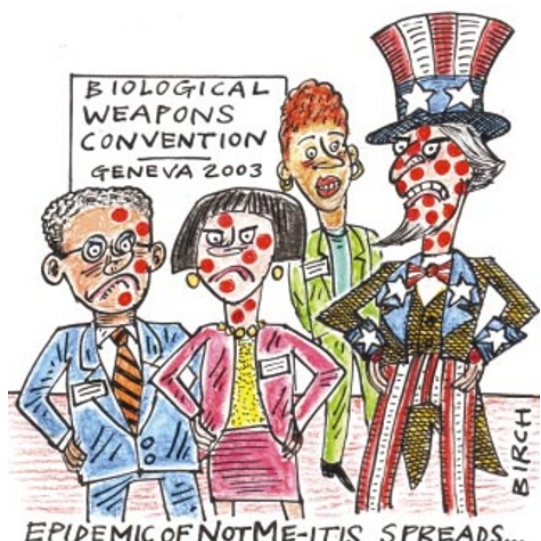

